\title{
Reef complexity influences distribution and habitat choice of the corallivorous seastar Culcita schmideliana in the Maldives
}

\author{
Enrico Montalbetti ${ }^{1,2}$ (i) $\cdot$ Luca Fallati $^{1,2}$ (1) Marco Casartelli $^{1} \cdot$ Davide Maggioni $^{1,2}$ (i) \\ Simone Montano ${ }^{1,2}$ (D) Paolo Galli ${ }^{1,2}$ (D) Davide Seveso $^{1,2}$ (D)
}

Received: 26 April 2021/Accepted: 31 January 2022/Published online: 24 February 2022

(C) The Author(s) 2022

\begin{abstract}
The cushion seastar Culcita schmideliana has gained major attention in the last few years because of its selective predation on juvenile corals, as well as its ability to generate large demographic assemblages, causing delays in coral recovery after large mortality events in the Republic of Maldives. However, a lack of data regarding the factors affecting its distribution and habitat selection still persists in this area. Here, we adopted a novel approach in the study of corallivorous seastar habitat selection that combined ecological and digital photogrammetry data. In this regard, we tested 3 different parameters as factors influencing seastar habitat choice in the South-East region of Faafu Atoll, Republic of Maldives, namely prey abundance, Linear Rugosity Index (LRI), and Average Slope (AS). The analysis of selectivity coefficient (Ei) of seastars for different habitat types showed a preference for reefs characterized by medium AS values $(\mathrm{Ei}=0.268)$, a LRI included between 2 and 2.5 $(\mathrm{Ei}=0.180)$, and a juvenile coral density ranging between 10 and 20 colonies $\mathrm{m}^{-2}(\mathrm{Ei}=0.154)$. A multiple linear regression analysis showed that different AS and LRI values explained the $43.1 \%\left(R^{2}=0.431, P=0.007\right)$ and the $48.1 \%\left(R^{2}=0.481, P=0.024\right)$ of variance in seastars abundance, respectively, while juvenile coral densities did not significantly affect this $\left(R^{2}=0.132, P=0.202\right)$. These
\end{abstract}

Topic Editor Stuart Sandin

Luca Fallati

luca.fallati@unimib.it

1 Department of Earth and Environmental Sciences (DISAT), University of Milano-Bicocca, Piazza della Scienza 1, Milano, Italy

2 MaRHE Center (Marine Research and High Education Centre), Magoodhoo Island, Faafu Atoll, Maldives results provide new information on the distribution and behaviour of an important corallivore of Maldivian reefs, such as $C$. schmideliana.

Keywords Corallivory $\cdot$ Cushion seastar $\cdot$ Habitat selection · Structure from Motion

\section{Introduction}

Predation on scleractinian corals is a common and well described ecological phenomenon in coral reef ecosystems (Rice et al. 2019). Corallivores are a trophic guild that encompass several taxa of vertebrate and invertebrate organisms adopting different strategies for coral consumption, i.e. removing mucus, tissue, or skeleton from the cnidarian prey (Cole et al. 2008; Rotjan and Lewis 2008). Among coral predators, corallivorous seastars represent a major plague for tropical reefs, in particular because of massive population outbreaks of the crown of thorns seastar (Acanthaster spp.), widely described to cause extensive coral mortality and shifts in coral assemblages, with implications for the whole reef community (Pratchett 2010; Kayal et al. 2012; Baird et al. 2013). The effects of corallivorous seastars are particularly grievous considering the large number of stressors affecting coral reefs' integrity in the last years, such as extreme climatic events and subsequent mass bleaching, or increased pollution (Carpenter et al. 2008; Patricola and Wehner 2018; Rice et al. 2019). In this context, it is important to consider the role of other coral feeding seastars, which, despite being still poorly studied, have been shown to affect reef resilience, in particular following large coral mortality events (Raj et al. 2018; Mah 2020). 
Cushion seastars (Culcita spp.) have been reported as resident organisms of Indo-Pacific coral reefs, representing a persisting element affecting benthic community structure and integrity (Raj et al. 2018; Bruckner and Coward 2019). Despite sharing some common features with crown of thorns seastars, such as the same predation modality and similar larval ecology, Culcita spp. generally consume lower amounts of coral prey per year than Acanthaster spp., and show a lower fecundity (Glynn and Krupp 1986; Birkeland and Lucas 1990; Quinn and Kojis 2003). However, cushion seastars show several peculiar feeding habits. In particular, they exert a preferential predation towards juvenile corals of a few genera, such as Pocillopora and Pavona, directly compromising the reef community structure and composition, as well as its recovery and resilience, as previously described for Maldivian coral reefs (Bruckner and Coward 2019; Montalbetti et al. 2019a). Indeed, in the Republic of Maldives Culcita schmideliana has gained special attention due to its ability to generate large demographic assemblages, with seastar densities often exceeding those recorded for Acanthaster planci in the same area, causing delays in reef recovery (Saponari et al. 2018; Bruckner and Coward 2019; Montalbetti et al. 2019b). Although the feeding preferences and different ecological patterns of $C$. schmideliana in the Maldivian archipelago have been already explored (Bruckner and Coward 2019; Montalbetti et al. 2019a; Montalbetti et al. 2021), the biotic and abiotic factors affecting the distribution of seastars are still unknown and need further study. Among these, prey availability has been hypothesized to represent an influencing factor controlling the distribution of cushion seastars, as demonstrated for other corallivorous organisms (Brooker et al. 2013; Wolf et al. 2014; Saponari et al. 2021). In addition, it has been hypothesized that the limited mobility of the cushion seastar, due to its round-shaped unarmed body, could compromise its ability to climb on and consume large coral colonies, preventing its ability to move on complex three-dimensional coral reefs (Thomassin 1976; Hawkins 2006). However, no experimental evidence has been provided so far.

Reef structural complexity is primarily influenced by coral species abundance and composition and by the physical conditions in which corals grow (Luckhurst and Luckhurst 1978; Todd 2008), and has been largely reported to influence biodiversity and community structure of coral reefs at multiple scales (Richardson et al. 2017; Price et al. 2019). Among the wide spectrum of habitat metrics used to quantify coral reefs habitat structure (Fukunaga et. al 2019), Linear Rugosity Index (LRI) and Average Slope (AS) represents two efficient indices to estimate habitat morphological complexity, providing a useful instrument that can numerically express bottom profile heterogeneity (Risk 1972; Friedman et al. 2012, Dustan et al. 2013; Burns et al. 2016; Pascoe et al. 2021). Linear rugosity has been defined as the comparison of a straight line transect with a flexible chain draped over the reef along the same transect, while the slope indicates the maximum rate of elevational change from each cell to its neighbours in units of degrees (Risk 1972; Burrough and McDonell 1998). In previous studies, these indices have been used to correlate reef complexity with the abundance of reef organisms, such as reef fishes (Risk 1972; Knudby and LeDrew 2007; Kuffner et al. 2007; Gonzalez-Riviero et al. 2017; Nugraha et al. 2020). Furthermore, recent advance in photogrammetry techniques and the application of Structure from Motion (SfM) algorithms allowed to obtain 3-dimensional (3D) models from sequences of overlapping images acquired from multiple viewpoints (Westoby et al. 2012; Fonstad et al. 2013; Leon et al. 2015; D'Urban et al. 2020). The application of these methods allows to calculate topographic metrics of reef areas with high precision, reducing costs and time necessary for surveys and providing more reliable values of reef complexity (Figueira et al. 2015; Storlazzi et al. 2016; Urbina-Barreto et al. 2021; Anelli et al. 2017; Rossi et al. 2021; Ventura et al. 2021).

The aim of the present study was to investigate different factors possibly influencing C. schmideliana distribution and habitat choice on Maldivian reefs. Specifically, we tested the hypothesis that $C$. schmideliana distribution could be influenced by biotic factors, such as the availability of juvenile coral prey, and abiotic factors, such as $3 \mathrm{D}$ complexity. For this purpose, we designed field experiments that combined digital modelling of reef geomorphology with ecological data, in order to characterize seastar selectivity for areas displaying different values of these biotic and abiotic parameters.

\section{Materials and methods}

\section{Study area}

The logistic base of the sampling activity was the MaRHE Center on the inhabited island of Magoodhoo ( $\left.3^{\circ} 4^{\prime} 49.08^{\prime \prime N}, 72^{\circ} 57^{\prime} 57.19^{\prime} \mathrm{E}\right)$, Faafu Atoll, Republic of Maldives (Fig. 1). In the South-East region of the atoll, six different sites were chosen, depending on their accessibility, their geographical location, and their geomorphological and environmental features. In particular, three sites, namely Dharamboodhoo reef, Dhigu reef, and Route 66 reef, were located on the external ocean-facing side of the atoll rim, usually subject to intense hydrodynamic conditions and characterised by steep walls, and thus classified as "outer" reefs. The other three sites, namely Freeclimbing reef, Maaga reef, and Sunny reef, were located inside the atoll rim, exhibiting typical low-energy 


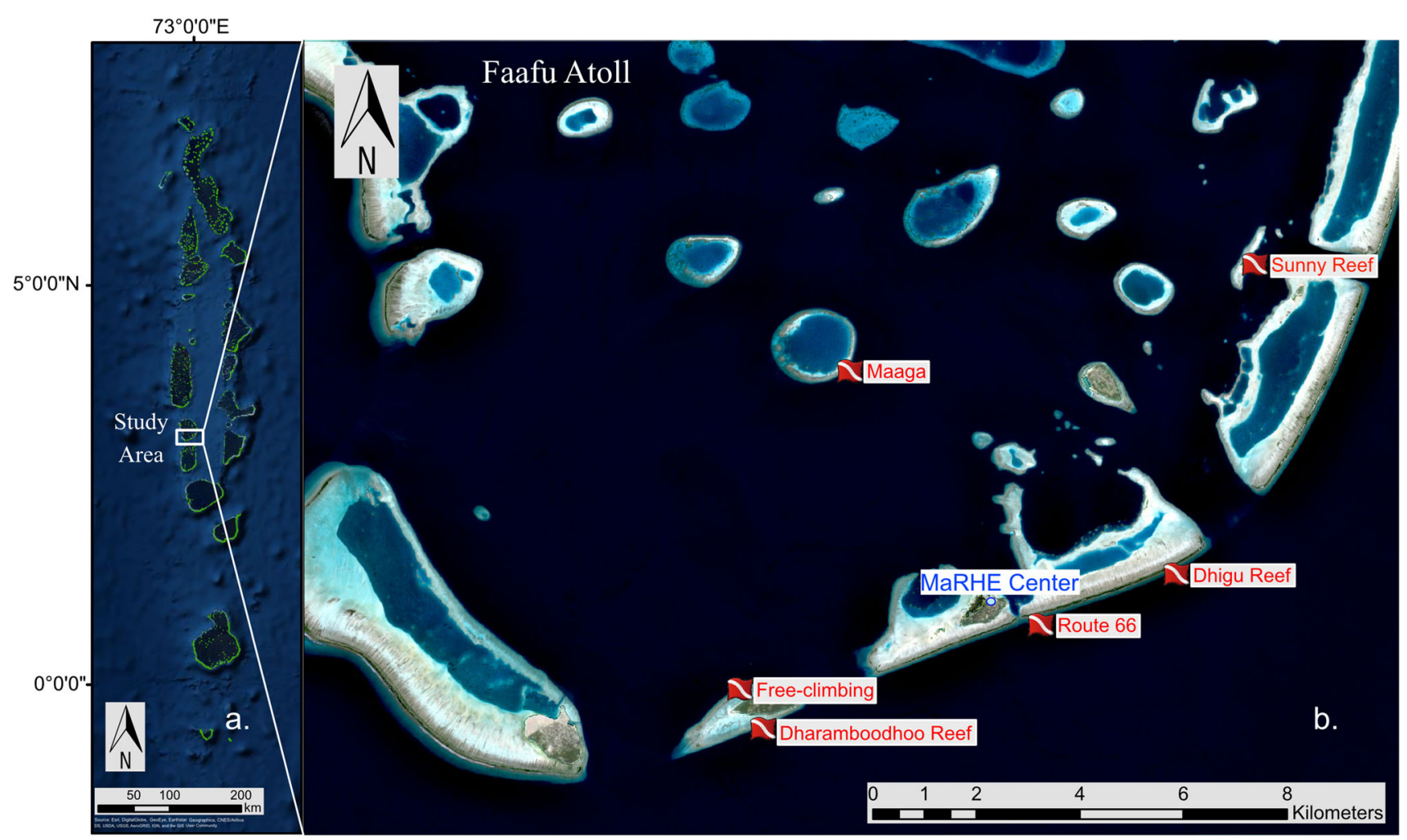

Fig. 1 a Satellite overview of the Maldivian archipelago. b Satellite close-up of the study area corresponding to South-Eastern region of Faafu Atoll. Sampling sites are marked in red. The position of

reef features with several different growth morphologies of corals, gentle slopes, and lagoon-patch reefs, and thus classified as "inner" reefs (Montano et al. 2012) (Fig. 1).

\section{Culcita schmideliana and juvenile coral abundance}

The distribution of $C$. schmideliana was estimated through the belt transect method at each sampling site. Specifically, three depth ranges $(0-5 \mathrm{~m}, 5-10 \mathrm{~m}$, and $10-15 \mathrm{~m})$ were considered for each site, and three $50 \times 4 \mathrm{~m}$ belt transects $\left(200 \mathrm{~m}^{2}\right.$ each) spaced at least $10-20 \mathrm{~m}$ apart were randomly placed at each depth zone, for a total of nine transects per site. In each transect, the total number of seastars encountered was recorded and the maximum diameter of each specimen was measured to the nearest centimeter (cm) using a ruler.

We considered as juvenile corals all those colonies with a maximum diameter lower than $10 \mathrm{~cm}$, since these specimens have been demonstrated to represent the preferred coral prey of Culcita spp. (Glynn and Krupp 1986; Norström et al. 2007; Montalbetti et al. 2019a). In order to estimate their abundance, a minimum of eight PVC quadrat of $1 \times 1 \mathrm{~m}$ were randomly placed within the area covered by each belt transect. Photographs of quadrats were taken
MaRHE Center is marked in blue (Basemap sources: Esri, DigitalGlobe, GeoEye, i-cubed, USDA FSA, USGS, AEX, Getmapping, Aerogrid, IGN, IGP, swisstopo, and the GIS User Community)

using a Canon G7X Mark II camera in a Fantasea FG7XII underwater housing, and then analysed with the ImageJ software (http://rsb.info.nih.gov/ij/). Each quadrat was scaled through dimensional references present on the PVC frame, and the maximum diameter of coral colonies within the square area was measured. The total number of juvenile corals was then recorded for each quadrat and the density per $\mathrm{m}^{2}$ was calculated for each depth zone and site.

\section{Underwater photogrammetry data acquisition}

The image acquisition was done following the metric tape as ground referencing, in correspondence with belt transects for each sampling site, using a Canon G7X Mark II camera in a Fantasea FG7XII underwater housing. A dive computer was used to record the depth at each end of the metric tape.

For each depth range, photographs were collected with a fixed acquisition protocol along two transects of $20 \mathrm{~m}$ (Fig. 2). Approximately 250 images were shot for each transect covering an area of $50 / 60 \mathrm{~m}^{2}$. Specifically, shots were taken continuously (with a rate of 1 photo every $1 / 2 \mathrm{~s}$ ) while swimming roughly two meters above the monitored areas beside two parallel paths. The camera lens 


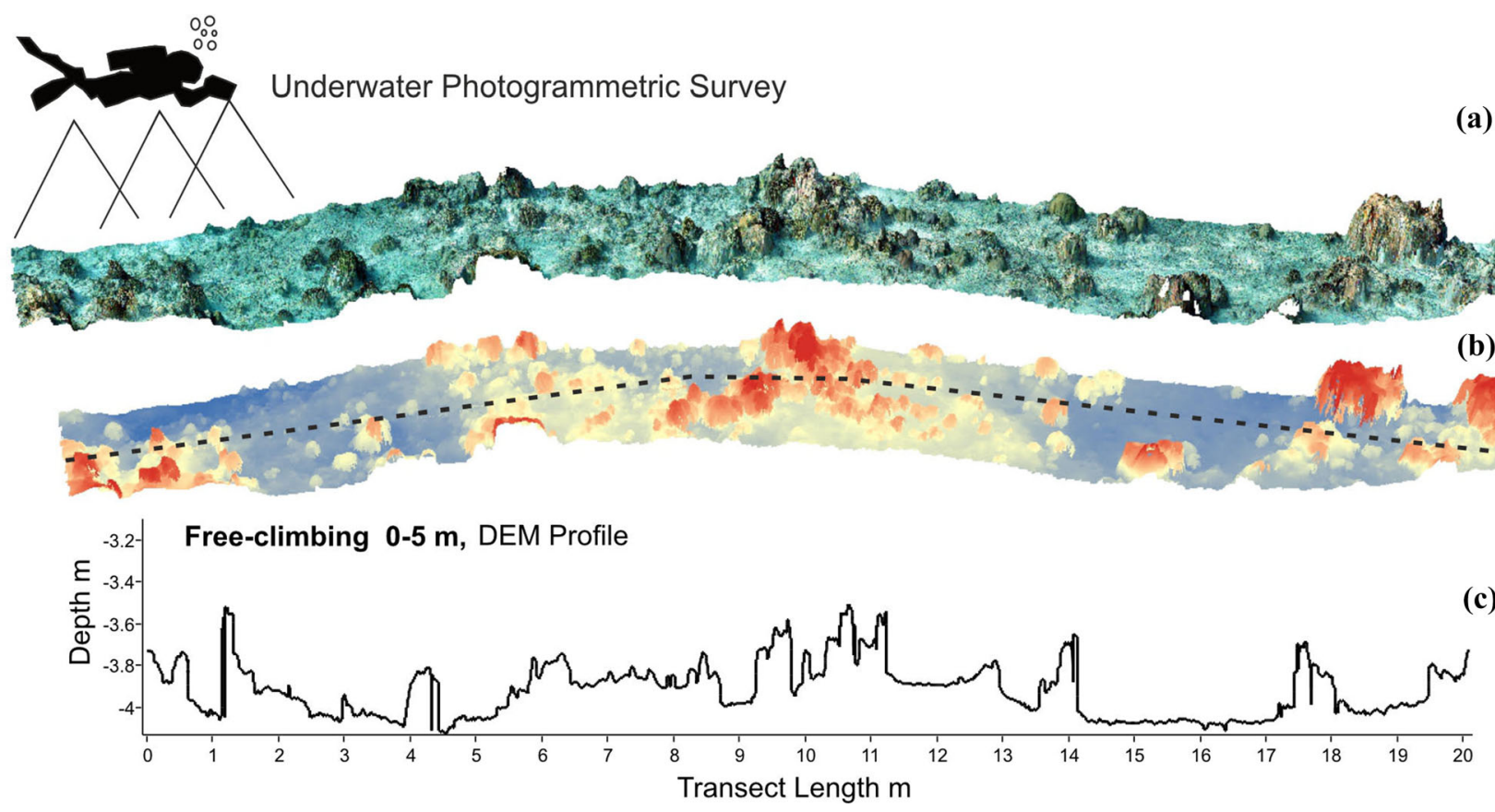

Fig. 2 Example of underwater images acquisition and data analysis of Freeclimbing reef $(0-5 \mathrm{~m}$ depth). a 3D model of the surface obtained from SfM processing. b Digital Elevation Model (DEM) representing the elevation gradient along the surveyed substrate. The dashed line indicates the virtual linear transect laid in correspondence

was kept parallel to the substrate, and the frontal overlap between two consecutive images was always higher than $80 \%$, while the lateral overlap was $70 \%$. Finally, to complete the survey, the diver took additional shots with the camera lens at a $45^{\circ}$ angle along the same paths. The overall time for image acquisition along a single transect was $\sim 20 \mathrm{~min}$.

\section{SfM data processing}

The software Agisoft Metashape Professional (https:// www.agisoft.com/) was used to perform SfM processing on the acquired images. The photo sets of each transect were processed following a standard SfM workflow (Figueira et al. 2015; Agisoft 2018; Fallati et al. 2020) divided into four main steps. 1) Overlapping images were aligned by identifying common points, using a high accuracy setting, achieving a 3D sparse point cloud. 2) A dense point cloud was generated from the sparse cloud, with high quality and moderate filter settings. 3) A Digital Elevation Model (DEM) was obtained from the dense cloud. 4) A highresolution orthomosaic was derived from the DEM as the final output. Moreover, in order to correctly scale the models, we used the metric tape as a known length object in the scene to create scale bars (Leon et al. 2015; Ferrari et al. 2016, 2017). Specifically, after the photos alignment, we placed on the tape four markers spaced $10 \mathrm{~cm}$ apart, in with the metric tape visible on the model. c Profile graph of the transect following the substrate contour. From the actual distance (3D) of this transect divided by the linear length (2D), the LRI is calculated

order to obtain DEMs and orthomosaics correctly scaled for each sampling site (Young et al. 2017). Then, the models were imported into a GIS environment for further analysis.

\section{Structural complexity evaluation}

The orthomosaics and DEMs were imported in ArcMap 10.8 (ESRI) and analyzed using the 3D Analyst Tools to extrapolate LRIs and AS along the transects (Burns et al., 2019; Magel et al. 2019; Fallati et al. 2020). First, a virtual transect of $20 \mathrm{~m}$ was laid along with the metric tape (clearly visible on screen thanks to the ultra-high resolution of the model, i.e. $0.02 \mathrm{~cm}$ ) on the central part of each processed orthomosaic and DEM. We used the function "Interpolate shape" to add the z-values, associated with the grids of the DEM, to the linear transect. Then, using the function "Add surface information" we calculated the 3D distance of the line. The LRI was calculated as the distance of a transect that considered changes in vertical surfaces (3D), divided by the linear distance of a transect (2D):

\section{$L R I=3$ LLength $\div 2$ DLength}

Values of LRI close to 0 indicate a lower three-dimensionality, while larger values indicate a higher degree of morphological complexity. 
In addition, the Average Slope (AS) along the transects was estimated using "Functional surface algorithms" included in the 3D Analyst Tools. AS was obtained by weighing each slope, calculated at each segment along the line, by its 3D length, and then determining the average. The output slope values were calculated as 'percent slope,' which is the rise divided by run (tangent $\theta$ ) multiplied by 100 (Burrough and McDonell 1998; Burns et al. 2015, 2016; Fallati et al. 2020). A small AS value reflects flat terrain, while a large AS value infers a steep terrain.

\section{Data analysis}

Data normality was verified through Shapiro-Wilk test. For purpose of comparison, seastars densities have been reported as seastars ha ${ }^{-1}$ (Bruckner and Coward 2019; Montalbetti et al. 2019b). Two-way ANOVA followed by Tukey's post-hoc test was performed to evaluate significant differences in seastar abundance in the different depth zones, and in different reef types (outer vs inner). The AS values obtained in different sites were grouped into three categories: "low" (< 1000), "medium" (1000-2000), and "high" (>2000). These were calculated considering the maximum and the minimum slope recorded, and symmetrically dividing this range into three bins. Similarly, LRI values were grouped in three categories $(<2,2-2.5$, and $>2.5$ ). In order to evaluate significant differences of seastar size between different AS categories, one-way ANOVA followed by Tukey's post-hoc test was performed. Kruskal-Wallis test followed by multiple pairwise comparisons was used to test significant differences in seastar size among different LRI categories, since data did not meet the assumption of normality (Zar 1999).

Seastar habitat preferences for different AS and LRI categories and different coral juvenile densities (classified in four density categories: $<5,5-10,10-20,>20$ juveniles $\mathrm{m}^{-2}$ ) were tested through Van der Ploeg and Scavia selectivity coefficient (Ei), following Lechowicz (1982). This coefficient is defined for a group $i$ as: $E i=\frac{\left[W i-\left(\frac{1}{n}\right)\right]}{\left[W i+\left(\frac{1}{n}\right)\right]}$

where Wi represents the value of Chesson's $\alpha$, and $n$ represents the number of habitat types (Lechowicz 1982). Chesson's $\alpha$ value (Wi) is defined as: $W i=\frac{r i}{P i} / \sum_{i} r i / P i$

where ri represents the frequency of a habitat category (AS, LRI, and juvenile density) in the environment, and Pi represents the frequency of the same habitat category in which the organism of interest is found (Chesson 1978). Values of selectivity coefficient range between -1 and 1 , with -1 meaning complete avoidance of a habitat category, and 1 meaning exclusive preference for a habitat type (Van der Ploeg and Scavia 1979).
A multiple linear regression analysis was performed to examine the relationship between the abundance of seastars and the AS, LRI, and juvenile coral density. All statistical analysis were performed using the SPSS software version 27 (IBM, New York), and data are presented as mean \pm standard error (SE), unless otherwise stated.

\section{Results}

\section{Habitat characterisation}

Thirty-six ultra-high-resolution 3D models were generated from the 7946 images acquired in correspondence of the six sampling sites. The average DEMs cell size was $1.2 \pm 0.5 \mathrm{~mm}$, while the orthomosaics had a pixel resolution of $0.4 \pm 0.07 \mathrm{~mm}$. The average LRI of the whole investigated area was $2.02 \pm 0.10$, with the maximum complexity reached in Dharamboodhoo reef (2.48 \pm 0.33$)$, which also showed the highest AS value $(2275.42 \pm 110.14)$, and the minimum 3-dimensionality recorded in Freeclimbing reef $(1.46 \pm 0.04)$, where the lowest AS value was also obtained (697.75 \pm 295.82$)$ (Table 1).

\section{Culcita schmideliana and juvenile coral abundance}

In the whole study area, an average density of $17.88 \pm 3.74$ coral juveniles $\mathrm{m}^{-2}$ was found (Table 1). Notably, the site with maximum and minimum juvenile density were again Dharamboodhoo reef $(26.14 \pm 8.80$ juveniles $\mathrm{m}^{-2}$ ) and Freeclimbing reef (3.07 \pm 1.63 juveniles $\mathrm{m}^{-2}$ ), respectively (Table 1 ).

A total number of 201 seastars were found in the study area, with an average density of $186.1 \pm 22.34$ seastars $\mathrm{ha}^{-1}$ (Table 1). Specifically, the site with the highest seastar density was Sunny reef $(283.32 \pm 75.15$ seastars $\mathrm{ha}^{-1}$ ), while the lowest density was recorded in Freeclimbing reef $\left(133.33 \pm 28.87\right.$ seastars $\left.\mathrm{ha}^{-1}\right)$. No significant differences were found in the number of $C$. schmideliana at different depths or in outer and inner sites and the combination of both factors (Two-way ANOVA, $\mathrm{P}>0.05)$.

\section{Size of seastars in different habitats}

The size of seastars was significantly different in relation to AS values and LRIs of the investigated sites (Fig. 3). In particular, C. schmideliana diameter was significantly larger in sites showing LRI value lower than 2 (KruskalWallis test $\mathrm{P}=0.033$ ) (Fig. 3a), and medium AS values (One-way ANOVA, F = 12.95 P < 0.0001) (Fig. 3b). 
Table 1 Average values ( \pm SE) of seastar densities, coral juvenile densities, AS values, and LRIs found in each sampling site

\begin{tabular}{lllclc}
\hline Site & Coral Cover $\%$ & Seastars/ha & Coral recruits/m2 & LRI & Slope Value \\
\hline Dharamboodhoo & 53.45 & $172.22 \pm 30.93$ & $26.14 \pm 8.80$ & $2.8 \pm 0.33$ & $2275.42 \pm 110.4$ \\
Dhigu Reef & 27.37 & $211.11 \pm 33.79$ & $15.66 \pm 5.8$ & $2.05 \pm 0.3$ & $1419.99 \pm 163.95$ \\
Freeclimbing & 19.8 & $133.33 \pm 28.87$ & $3.7 \pm 1.63$ & $1.46 \pm 0.04$ & $697.5 \pm 295.82$ \\
Maaga & 10.01 & $144.5 \pm 30.93$ & $12.61 \pm 7.25$ & $1.87 \pm 0.20$ & $1632.5 \pm 529.93$ \\
Route 66 & 24.68 & $172.18 \pm 5.56$ & $25.73 \pm 11.98$ & $2.11 \pm 0.14$ & $1451.35 \pm 123.60$ \\
Sunny Reef & 35.38 & $283.32 \pm 75.15$ & $24.08 \pm 6.77$ & $2.16 \pm 0.17$ & $2266.88 \pm 319.28$ \\
Total & $28.46 \pm 6.6$ & $186.1 \pm 22.34$ & $17.88 \pm 3.74$ & $2.2 \pm 0.10$ & $1623.96 \pm 242.70$ \\
\hline
\end{tabular}

(a)

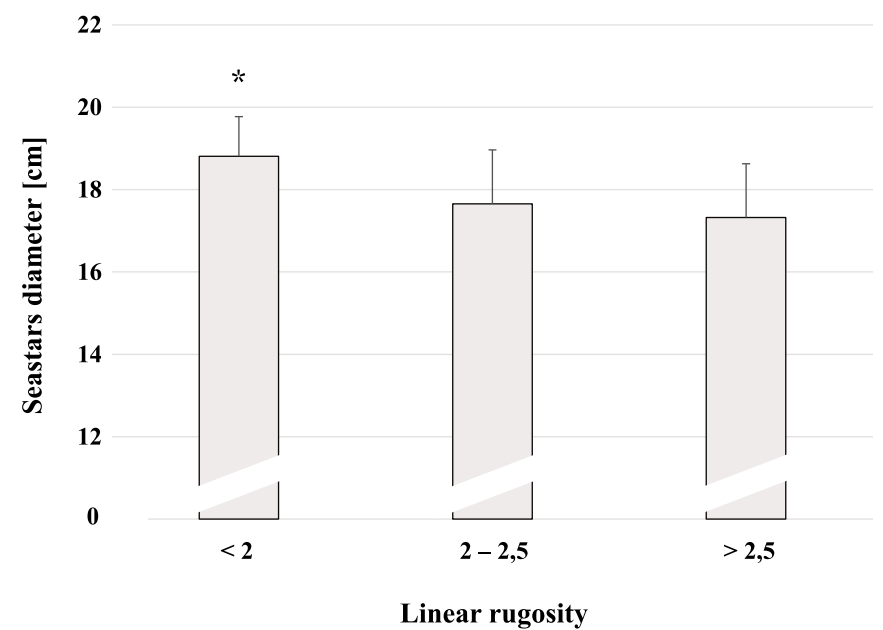

Fig. 3 Average diameter $( \pm \mathrm{SE})$ of seastars found in areas a with different values of LRI and $\mathbf{b}$ with different AS values. KruskalWallis test followed by multiple pairwise comparisons was used to test significant differences in seastars diameter in areas with different

\section{Culcita schmideliana habitat preferences}

Three main factors and their influence on C. schmideliana choice of habitat were tested through the selectivity coefficient (Ei) (Fig. 4). Seastars exhibited a general preference for habitat with medium AS values $(\mathrm{Ei}=0.268)$, a marked avoidance for habitat with low AS values $(\mathrm{Ei}=-0.353)$, and a slight avoidance of areas with high AS values (Ei = 0.118) (Fig. 4a).

Considering seastar preferences for habitats with different degrees of seafloor morphological complexity, the preferred habitat of $C$. schmideliana was characterized by a LRI value included between 2 and 2.5, with a $\mathrm{Ei}=0.180$ (Fig. 4b). Areas with a LRI larger than 2.5, thus meaning those with the highest complexity, were avoided by seastars and gave an Ei value of -0.213 (Fig. 4b). Moreover, areas showing the lowest three-dimensionality, considered as those with a LRI lower than 2, gave an Ei close (b)

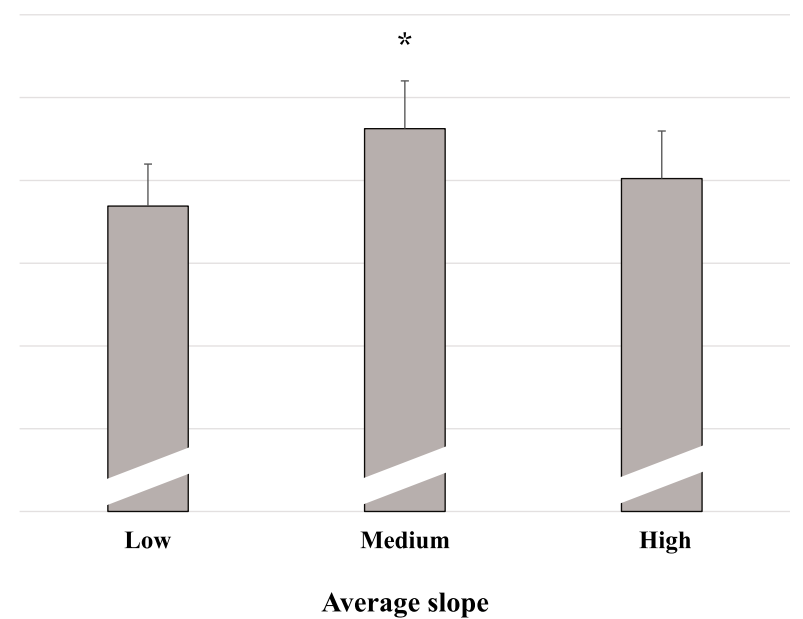

LRI $(P<0.033)$. One-way ANOVA followed by Tukey's post-hoc test was used to test significant differences in diameters of seastars found in areas with different AS values $(P<0.0001)$. Significant differences are marked with $*$ in proximity of each relative column

to $0(\mathrm{Ei}=-0.025)$, indicating a level of selectivity coefficient close to random (Fig. 4b).

Concerning juvenile corals density, the preferred habitats of $C$. schmideliana were those characterized by a density of juveniles $\mathrm{m}^{-2}$ included between 10 and 20 $(\mathrm{Ei}=0.154)$, while areas with the lowest juvenile density were avoided $(\mathrm{Ei}=-0.269)(\mathrm{Fig} .4 \mathrm{c})$. Areas with more than 20 juveniles $\mathrm{m}^{-2}$, and areas with a juvenile density between 5 and $10 \mathrm{~m}^{-2}$, showed a slight preference and avoidance, respectively, even if close to random, with values of $\mathrm{Ei}=0.079$ for the first, and $\mathrm{Ei}=-0.059$ for the latter (Fig. 4c).

The multiple linear regression analysis allowed us to define which of the factors considered exerted the highest influence on the cushion seastar abundance in the study area. A significant regression equation was found for AS values $\left(\mathrm{F}_{(3.28)}=2.8, \mathrm{R}^{2}=0.431, \mathrm{P}=0.007\right)$ (Fig. 5a), and for linear rugosity $\left(\mathrm{F}_{(3.28)}=2.8, \mathrm{R}^{2}=0.481, \mathrm{P}=0.024\right)$ 
(a)

\section{Average slope}

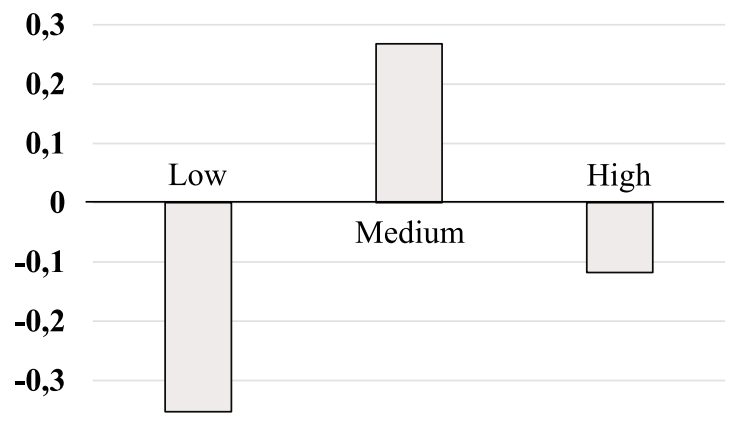

$-0,4$

(b)

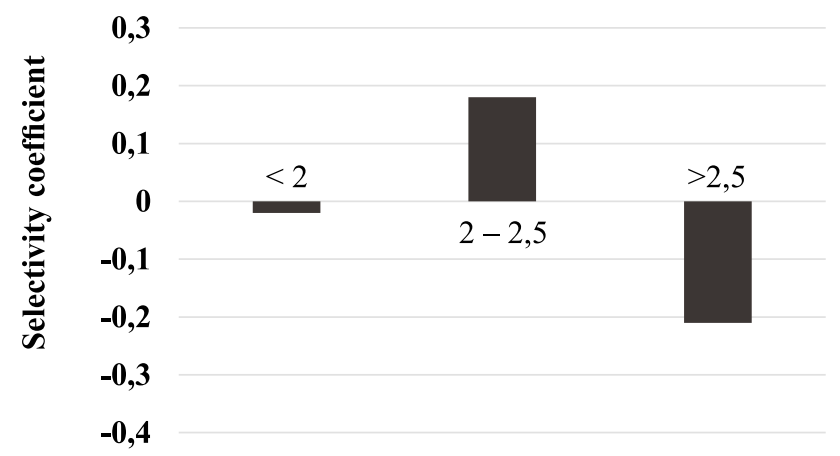

(c)

\section{Coral juvenile density}

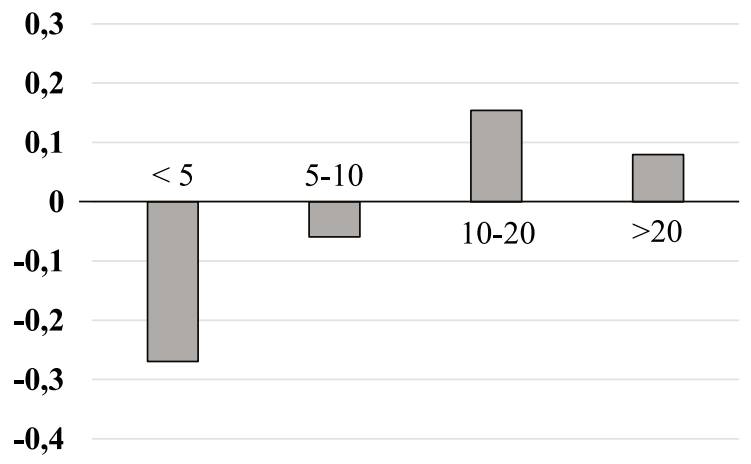

Fig. 4 Values of Van der Ploeg and Scavia Selectivity coefficient ($1=$ complete avoidance; $0=$ random choice $+1=$ exclusive preference) of seastars for areas with a different AS values $\mathbf{b}$ different LRIs and $\mathbf{c}$ different densities of coral juveniles

(Fig. 5b), showing that the $43.1 \%$ and the $48.1 \%$ of the variance in seastar abundance was explained by differences in AS values and LRI, respectively. The regression equation to assess the variation in seastar abundance in relation to the variation of juvenile coral densities resulted to be not significant $\left(\mathrm{F}_{(3.28)}=2.8, \mathrm{R}^{2}=0.132, \mathrm{P}=0.202\right)($ Fig. 5c). (a)

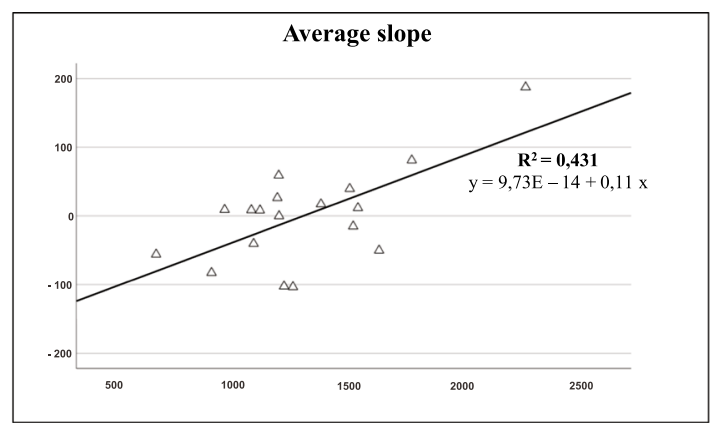

(b)

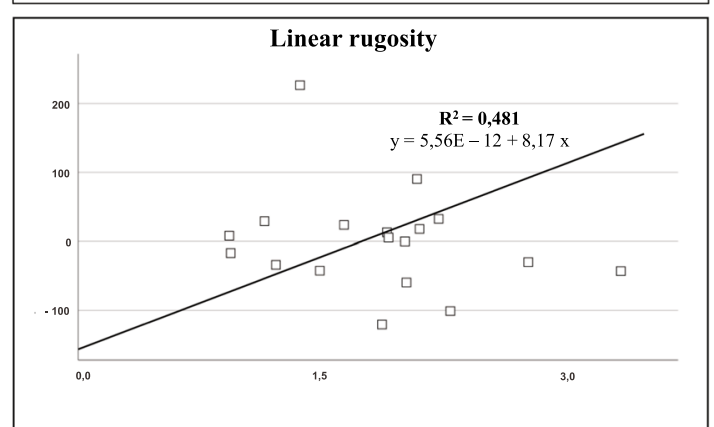

(c)

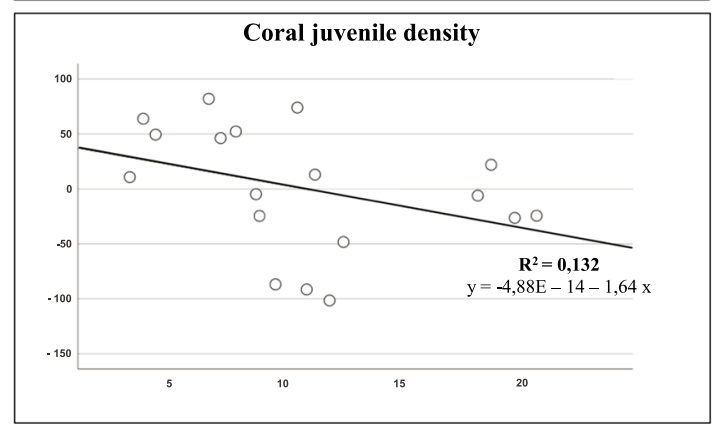

Fig. 5 Multiple linear regression analysis displayed as partial regression plots. Relationships between seastar density and a AS values $(P=0.007)$ b LRI $(P=0.024)$ and $\mathbf{c}$ juvenile corals $\mathrm{m}^{-2}$ $(P=0.202)$. All data relative to the three independent variables have been log-transformed in the partial regression plots. Continuous lines indicate partial regression of each independent variable

\section{Discussion}

Among the wide range of disturbances that have affected the integrity of Maldivian reefs in the last decades, including mass bleaching events (Tkachenko 2015; Perry and Morgan 2017), coral diseases (Seveso et al. 2012, 2015; Montano et al. 2015, 2016), and land reclamation (Fallati et al. 2017), corallivorous outbreaks represent one of the greatest threats, and $C$. schmideliana has certainly played a fundamental role (Saponari et al. 2014; Saponari et al. 2018; Montalbetti et al. 2019a; Caragnano et al. 2021). However, the factors driving the distribution and the habitat choice of this organism still remain unclear. In this study, we analyzed the role of different geomorphological parameters in the habitat selection of $C$. schmideliana, through the use of novel photogrammetry 
techniques that allowed us to accurately reconstruct the reef topology. In addition, prey availability has also been investigated as a possible influencing factor.

The abundance of seastars in the investigated area was not affected by the site exposure, as a comparable number of individuals was observed in inner and outer reefs. Furthermore, seastar distribution resulted to be relatively homogeneous at different depth ranges, similar to a previous study in which seastar density did not change significantly within the first $30 \mathrm{~m}$ of depth (Montalbetti et al. 2019a). Although the cushion seastar has been occasionally reported at depths of up to $50-60 \mathrm{~m}$, it seems to prefer shallowest areas with high coral cover, probably due to the larger availability of coral prey (Thomassin 1976; Glynn and Krupp 1986). Moreover, since larval settlement is influenced by sea bottom substrate, it could also represent an influencing factor of adult seastar distribution in different reef habitats and depths (Ebert 1983). Indeed, it has been shown that settlement of Acanthaster cf. solaris larvae in relatively shallow waters could forewarn seastar population eruptions and tend to increase with the proportion of coral rubble, while decreasing with the proportion of live hard coral (Wilmes et al. 2020). Since very little is known about $C$. schmideliana larval settlement and its success on different substrates, the possibility that early life stage population of seastars can influence adult distribution needs to be further explored.

As long as the ability to move on complex reefs is a key component of the behaviour of corallivorous echinoderms, our results about seastar size suggested that C. schmideliana mobility could be influenced by body anatomy. Indeed, seastars found in areas with a low morphological complexity were significantly larger compared to those found in more complex areas, suggesting that larger specimens could be prevented from moving within complex reef frames. Culcita schmideliana is a round-shaped un-armed seastar, and these peculiar anatomical features have been hypothesized to represent a strong influencing factor in its distribution and habitat choice (Quinn and Kojis 2003; Montalbetti et al. 2019a). Limited mobility caused by anatomical features could also explain the lower average size of seastars found in areas with elevated AS values. The largest specimens were found in areas with medium AS values, and smaller seastars were found in reefs with low degree of inclination. These results strengthen the hypothesis that body size could represent a key element of $C$. schmideliana habitat choice. Echinoderms have a strict connection with reef structure due to different ethological aspects, such as diurnal cryptic behaviour that is often reported for coral predator seastars (Dumont et al. 2007; Pratchett et al. 2017). In particular, crown of thorns often showed a radical behavioral change between diurnal and nocturnal conditions, being hidden within reef crevices and cavities during the day and getting out for preying during night (Rivera-Posada et al. 2014; Burn et al. 2020). Diurnal crypticity has been reported also for cushion seastars and other corallivore invertebrates (Wolf et al. 2014; Enochs and Glynn 2017). In this context, we hypothesized that seastar anatomical features and the need of hiding during daylight hours could be correlated with the choice of habitats with different degrees of steepness and 3-dimensionality, although this aspect should be further investigated.

Morphological complexity has been reported as an ecological factor correlated with fish assemblage biodiversity and biomass in different tropical regions, such as the Caribbean Sea and Indian Ocean (Harborne et al. 2012; Darling et al. 2017). Furthermore, reef 3-dimensionality has been addressed as a strong predictor of abundance, biomass, diversity, and trophic structure of diurnal, noncryptic reef fishes (Darling et al. 2017; Nugraha et al. 2020). However, how these morphological factors can influence the distribution of mobile invertebrates is a far less examined question (Stella et al. 2011; Graham and Nash 2013). Our results suggest that seastars tend to avoid habitats with high values of linear rugosity, highlighting once again that the anatomical shape of seastars could play a crucial role in habitat selection. The same pattern of distribution has previously been observed for other reef invertebrates such as sea urchins, which seem to aggregate more frequently and more abundantly on reefs with moderate rugosity due to their scarce ability to climb on complex coralline structures (Weil et al. 2005; Dumont et al. 2007). On the contrary, for smaller benthic organisms, such as penaeid shrimps, an increase in substrate rugosity and complexity coincided with an increased differentiation of their spatial distribution due to a larger number of micro-habitats suitable for prey, thus allowing the coexistence of several prawn species, each exploiting different microhabitats and patches (Gribble et al. 2004, 2007). In the case of $C$. schmideliana, the preferential choice of habitats with a medium value of rugosity could result from the sum of different factors, such as body anatomy, behavioral traits, and larval settlement. In addition, selectivity coefficient values indicated a well-defined pattern of avoidance by seastars of reef areas with low and high AS values, while habitats displaying medium AS values were preferred. The role of reef inclination in determining the distribution patterns of benthic organisms has been largely ignored so far, but our data suggest that $C$. schmideliana could selectively prefer areas with medium AS values. We hypothesize that this selection may be related to the settlement of juvenile seastars. Juveniles recruitment patterns have been shown to influence adult distribution in several echinoderm species, and are controlled by different factors, such as availability of food, 
sedimentation rates, and reef complexity (Glynn and Krupp 1986; Birkeland and Lucas 1990; Klumpp and McKinnon 1992; Quinn and Kojis 2003).

Finally, prey availability has widely been reported to influence corallivorous seastar distribution and movement on coral reefs (Burn et al. 2020; Ling et al. 2020). In the Maldives, C. schmideliana was observed preying preferentially on small coral colonies (diameter $<10 \mathrm{~cm}$ ) of Pocillopora spp. and Pavona spp., although it was able to consume a large number of different coral genera (Montalbetti et al. 2019a). Here, seastar preference for reef areas with a number of favourite preys larger than $10 \mathrm{~m}^{-2}$ was observed, confirming previous findings. Coral juvenile quantification through photoquadrats analysis resulted to be an effective and quick method to investigate large portions of reef. Possible errors related to this methodology, in particular considering a qualitative identification of juvenile corals, should be taken into account in future studies, as described in Burgess et al. (2010). In this work, a coral identification at the genus level was not performed, but in future research a possible correlation between seastar densities and abundance of different coral genera should be explored.

However, taken together, our results indicate that both the morphological factors considered, namely LRIs and AS values, resulted to be more effective in explaining variance in C. schmideliana densities, compared to prey availability. Therefore, the substrate complexity and inclination mostly affected the habitat choice of $C$. schmideliana, rather than food abundance. It is important to emphasize that this kind of hierarchical approach has been rarely applied to seastar habitat choice studies. Previously, it was observed that juveniles of two temperate water seastar species, Pisaster ochraceus and Evasterias troschelii, chose their habitat primarily depending on bottom complexity in order to escape predators, and once they attained a size unsuitable for predators, they select their habitat mainly on the base of prey availability (Rogers and Elliot 2013). However, the information about predation on C. schmideliana are still scarce, whereas it is known that Acanthaster spp. are preyed by different organisms at different life stages (Cowan et al. 2017; Balu et al. 2021). It is reasonable to hypothesize a similar predatory pressure on Culcita spp., at least at the larval stage, considering that these two corallivorous seastars share many ecological similarities (Glynn and Krupp 1986). Therefore, we cannot exclude that predation could represent an influencing factor of habitat choice by $C$. schmideliana, and further investigations are needed to clarify this point.

In conclusion, this study provided new insights about the distribution and the habitat choice of an important corallivore of the Maldivian archipelago, partially confirming previous untested hypotheses, and adding new information that could be useful for a better understanding of the behaviour of this understudied organism. In particular, we found that body anatomy could represent a driver of habitat choice, which, combined with other behavioral traits of the seastar, could influence the distribution of these organisms. Furthermore, despite preferring areas with larger availability of food, C. schmideliana selects its habitat primarily on the base of the morphological features of the reef, like 3-dimensional complexity and steepness. Our results provide new important information about the ecology of corallivore organisms that should be considered in developing programmes for the monitoring and prevention of the impacts of this plague in Maldivian coral reefs.

Acknowledgements The authors wish to thank all the staff of Marine Research and High Education Center (MaRHE Center) of the University of Milano-Bicocca, in Magoodhoo Island (Faafu, Maldives) for the logistical help provided, as well as the population and the community of the island for supporting this research. The authors are also grateful to Luca Saponari and Inga Dehnert for technical support during the sampling activities.

\section{Declarations}

Conflict of interest The authors declare that they have no known competing financial interests or personal relationships that could have appeared to influence the work reported in this paper.

Open Access This article is licensed under a Creative Commons Attribution 4.0 International License, which permits use, sharing, adaptation, distribution and reproduction in any medium or format, as long as you give appropriate credit to the original author(s) and the source, provide a link to the Creative Commons licence, and indicate if changes were made. The images or other third party material in this article are included in the article's Creative Commons licence, unless indicated otherwise in a credit line to the material. If material is not included in the article's Creative Commons licence and your intended use is not permitted by statutory regulation or exceeds the permitted use, you will need to obtain permission directly from the copyright holder. To view a copy of this licence, visit http://creativecommons. org/licenses/by/4.0/.

\section{References}

Agisoft, (2018) Agisoft photoscan user manual. Prof Edit Ver 1:4 Anelli M, Julitta T, Fallati L, Galli P, Rossini M, Colombo R (2017) Towards new applications of underwater photogrammetry for investigating coral reef morphology and habitat complexity in the Myeik Archipelago, Myanmar. Geocart Inter 34(5):459-472

Baird AH, Pratchett MS, Hoey AS, Herdiana Y, Campbell SJ (2013) Acanthaster planci is a major cause of coral mortality in Indonesia. Coral Reefs 32(3):803-812

Balu V, Messmer V, Logan M, Hayashida-Boyles AL, Uthicke S (2021) Is predation of juvenile crown-of-thorns seastars (Acanthaster cf. solaris) by peppermint shrimp (Lysmata vittata) dependent on age, size, or diet? Coral Reefs 1-9

Birkeland C, Lucas J (1990) Acanthaster planci: major management problem of coral reefs. CRC Press, Boca Raton, Florida 
Brooker RM, Jones GP, Munday PL (2013) Prey selectivity affects reproductive success of a corallivorous reef fish. Oecologia 172(2):409-416

Bruckner AW, Coward G (2019) Abnormal density of Culcita schmideliana delays recovery of a reef system in the Maldives following a catastrophic bleaching event. Mar Fres Res 70(2):292-301

Burgess SC, Osborne K, Sfiligoj B, Sweatman H (2010) Can juvenile corals be surveyed effectively using digital photography?: implications for rapid assessment techniques. Environ Monit Assess 171(1):345-351

Burn D, Matthews S, Caballes CF, Chandler JF, Pratchett MS (2020) Biogeographical variation in diurnal behaviour of Acanthaster planci versus Acanthaster cf solaris. PLoS ONE 15(2):e0228796

Burns JHR, Delparte D, Gates RD, Takabayashi M (2015) Integrating structure-from-motion photogrammetry with geospatial software as a novel technique for quantifying $3 \mathrm{D}$ ecological characteristics of coral reefs. PeerJ 7:e1077

Burns JHR, Delparte D, Kapono L, Belt M, Gates RD, Takabayashi M (2016) Assessing the impact of acute disturbances on the structure and composition of a coral community using innovative 3D reconstruction techniques. Methods Oceanograph 15-16:49-59. https://doi.org/10.1016/j.mio.2016.04.001

Burns JHR, Fukunaga A, Pascoe KH, Runyan A, Craig BK, Talbot J, Pugh A, Kosaki RK (2019) 3d habitat complexity of coral reefs in the northwestern hawaiian islands is driven by coral assemblage structure. ISPRS Annals of the Photogrammetry. Remote Sensing Spatial Inform Sci 42(2/W10):61-67. https://doi.org/10. 5194/isprs-archives-XLII-2-W10-61-2019

Burrough PA, McDonell RA (1998) Principles of Geographical Information Systems. Oxford University Press, New York

Caragnano A, Basso D, Spezzaferri S, Hallock P (2021) A snapshot of reef conditions in North Ari Atoll (Maldives) following the 2016 bleaching event and Acanthaster planci outbreak. Mar Freshwat Res

Carpenter KE, Abrar M, Aeby G, Aronson RB, Banks S, Bruckner A et al (2008) One-third of reef-building corals face elevated extinction risk from climate change and local impacts. Science 321(5888):560-563

Chesson J (1978) Measuring preference in selective predation. Ecol 59(2):211-215

Cole AJ, Pratchett MS, Jones GP (2008) Diversity and functional importance of coral-feeding fishes on tropical coral reefs. Fish Fisher 9(3):286-307

Cowan ZL, Ling SD, Dworjanyn SA, Caballes CF, Pratchett MS (2017) Interspecific variation in potential importance of planktivorous damselfishes as predators of Acanthaster sp eggs. Coral Reefs 36(2):653-661

D'Urban JT, Williams GJ, Walker-Springett G, Davies AJ (2020) Three-dimensional digital mapping of ecosystems: a new era in spatial ecology. Proc Roy Soc b: Biol Sci 287(1920):20192383

Darling ES, Graham NAJ, Januchowski-Hartley FA, Nash KL, Pratchett MS, Wilson SK (2017) Relationships between structural complexity, coral traits, and reef fish assemblages. Coral Reefs 36:561-575

Dumont CP, Himmelman JH, Robinson SM (2007) Random movement pattern of the sea urchin Strongylocentrotus droebachiensis. J Exp Mar Bio Eco 340(1):80-89

Dustan P, Doherty O, Pardede S (2013) Digital Reef Rugosity Estimates Coral Reef Habitat Complexity. PLoS ONE 8(2):1-10. https://doi.org/10.1371/journal.pone.0057386

Ebert TA (1983) Recruitment in Echinoderm. In Jangoux M and Lawrence JM (1983) Echinoderm studies. CRC Press, London, UK
Enochs IC, Glynn PW (2017) Corallivory in the eastern Pacific. Coral Reefs of the Eastern Tropical Pacific. Springer, Dordrecht, pp 315-337

Fallati L, Savini A, Sterlacchini S, Galli P (2017) Land use and land cover (LULC) of the Republic of the Maldives: first national map and LULC change analysis using remote-sensing data. Env Mon Ass 189(8):1-15

Fallati L, Saponari L, Savini A, Marchese F, Corselli C, Galli P (2020) Multi-Temporal UAV Data and object-based image analysis (OBIA) for estimation of substrate changes in a postbleaching scenario on a maldivian reef. Rem Sens 12(13):2093

Ferrari R, Bryson M, Bridge T, Hustache J, Williams SB, Byrne M, Figueira W (2016) Quantifying the response of structural complexity and community composition to environmental change in marine communities. Glob Chan Bio 22(5):1965-1975

Ferrari R, Figueira WF, Pratchett MS, Boube T, Adam A, Kobelkowsky-Vidrio T, Doo SS, Atwood TB, Byrne M (2017) $3 \mathrm{D}$ photogrammetry quantifies growth and external erosion of individual coral colonies and skeletons. Sci Rep 7(1):1-9

Figueira W, Ferrari R, Weatherby E, Porter A, Hawes S, Byrne M (2015) Accuracy and precision of habitat structural complexity metrics derived from underwater photogrammetry. Rem Sens 7(12):16883-16900

Fonstad MA, Dietrich JT, Courville BC, Jensen JL, Carbonneau PE (2013) Topographic structure from motion: a new development in photogrammetric measurement. Earth Surf Proces Landfor 38(4):421-430

Friedman A, Pizarro O, Williams SB, Johnson-Roberson M (2012) Multi-scale measures of rugosity, slope and aspect from benthic stereo image reconstructions. PLoS ONE 7(12):e50440. https:// doi.org/10.1371/journal.pone.0050440

Fukunaga A, Burns JHR, Craig BK, Kosaki RK (2019) Integrating three-dimensional benthic habitat characterization techniques into ecological monitoring of coral reefs. J Marine Sci Eng. https://doi.org/10.3390/jmse7020027

Glynn PW, Krupp DA (1986) Feeding biology of a Hawaiian sea star corallivore, Culcita novaeguineae (Muller \& Troschel). J Exp Mar Bio Eco 96(1):75-96

González-Rivero M, Harborne AR, Herrera-Reveles A, Bozec YM, Rogers A, Friedman A, Ganase A, Hoegh-Guldberg O (2017) Linking fishes to multiple metrics of coral reef structural complexity using three-dimensional technology. Sci Rep 7(1):13965

Graham NAJ, Nash KL (2013) The importance of structural complexity in coral reef ecosystems. Coral Reefs 32(2):315-326

Gribble NA (2004) A spatially explicit multi-competitor coexistence model of penaeid (shrimp) distribution on the Australian Great Barrier Reef. Ecol Model 177(1-2):61-74

Gribble NA, Wassenberg TJ, Burridge C (2007) Factors affecting the distribution of commercially exploited penaeid prawns (shrimp) (Decapod: Penaeidae) across the northern Great Barrier Reef. Australia Fisher Res 85(1-2):174-185

Harborne AR, Mumby PJ, Ferrari R (2012) The effectiveness of different meso-scale rugosity metrics for predicting intra-habitat variation in coral-reef fish assemblages. Env Bio Fish 94(2):431-442

Hawkins SV (2006) Feeding Preference of the Cushion Star, Culcita Novaeguineae in Mo'orea. Univ Ber Press, Berkeley, California

Kayal M, Vercelloni J, De Loma TL, Bosserelle P, Chancerelle Y, Geoffroy S et al (2012) Predator crown-of-thorns starfish (Acanthaster planci) outbreak, mass mortality of corals, and cascading effects on reef fish and benthic communities. PLoS ONE 7(10):e47363

Klumpp DW, McKinnon AD (1992) Community structure, biomass and productivity of epilithic algal communities on the Great 
Barrier Reef: dynamics at different spatial scales. Mar Eco Prog Ser 77-89

Knudby A, LeDrew E (2007) Measuring structural complexity on coral reefs. Proc Amer Soc Underwat Sci. 181-188

Kuffner IB, Brock JC, Grober-Dunsmore R, Bonito VE, Hickey TD, Wright CW (2007) Relationships between reef fish communities and remotely sensed rugosity measurements in Biscayne National Park, Florida, USA. Env Bio Fish 78(1):71-82

Lechowicz MJ (1982) The sampling characteristics of electivity indices. Oecologia 52(1):22-30

Leon JX, Roelfsema CM, Saunders MI, Phinn SR (2015) Measuring coral reef terrain roughness using "Structure-from-Motion" close-range photogrammetry. Geomorph 242:21-28

Ling SD, Cowan ZL, Boada J, Flukes EB, Pratchett MS (2020) Homing behaviour by destructive crown-of-thorns starfish is triggered by local availability of coral prey. Proc Royal Soc b: Biol Sci 287(1938):20201341

Luckhurst BE, Luckhurst K (1978) Analysis of the influence of substrate variables on coral reef fish communities. Mar Bio 49(4):317-323

Magel JMT, Burns JHR, Gates RD, Baum JK (2019) Effects of bleaching-associated mass coral mortality on reef structural complexity across a gradient of local disturbance. Sci Rep $9(1): 2512$

Mah CL (2020) New species, occurrence records and observations of predation by deep-sea Asteroidea (Echinodermata) from the North Atlantic by NOAA ship Okeanos Explorer. Zootaxa 4766(2):4766

Montalbetti E, Saponari L, Montano S, Seveso D (2019a) Another diner sits at the banquet: evidence of a possible population outbreak of Culcita sp. Agassiz 1836 in Maldives. Galaxea J Coral Reef Stud 21(1):5-6

Montalbetti E, Saponari L, Montano S, Maggioni D, Dehnert I, Galli $P$, Seveso D (2019b) New insights into the ecology and corallivory of Culcita sp. (Echinodermata: Asteroidea) in the Republic of Maldives. Hydrobiologia 827(1):353-365

Montalbetti E, Vencato S, Saponari L, Seveso D (2021) First observation of cushion seastar Culcita sp. spawning simultaneously with other Echinoderms species in Central Indian Ocean. Galaxea J Coral Reef Stud. 22(1):51-52

Montano S, Strona G, Seveso D, Galli P (2012) First report of coral diseases in the Republic of Maldives. Dis Aquat Organ 101(2):159-165

Montano S, Strona G, Seveso D, Maggioni D, Galli P (2015) Slow progression of black band disease in Goniopora cf. columna colonies may promote its persistence in a coral community. Mar Biodiv 45(4):857-860

Montano S, Strona G, Seveso D, Maggioni D, Galli P (2016) Widespread occurrence of coral diseases in the central Maldives. Mar Freshwat Res 67(8):1253-1262

Norström AV, Lokrantz J, Nyström M et al (2007) Influence of dead coral substrate morphology on patterns of juvenile coral distribution. Mar Biol 150:1145-1152

Nugraha WA, Mubarak F, Husaini E, Evendi H (2020) The correlation of coral reef cover and rugosity with coral reef fish density in East Java Waters. J Ilm Perik Kelaut 12(1):131-139

Pascoe KH, Fukunaga A, Kosaki RK, Burns JHR (2021) 3D assessment of a coral reef at Lalo Atoll reveals varying responses of habitat metrics following a catastrophic hurricane. Sci Rep 11(1):12050. https://doi.org/10.1038/s41598-02191509-4

Patricola CM, Wehner MF (2018) Anthropogenic influences on major tropical cyclone events. Nature 563(7731):339-346

Perry CT, Morgan KM (2017) Post-bleaching coral community change on southern Maldivian reefs: is there potential for rapid recovery? Coral Reefs 36(4):1189-1194
Pratchett MS (2010) Changes in coral assemblages during an outbreak of Acanthaster planci at Lizard Island, northern Great Barrier Reef (1995-1999). Coral Reefs 29(3):717-725

Pratchett MS, Caballes CF, Wilmes JC, Matthews S, Mellin C, Sweatman H et al (2017) Thirty years of research on crown-ofthorns starfish (1986-2016): scientific advances and emerging opportunities. Diversity 9(4):41

Price DM, Robert K, Callaway A, Lo lacono C, Hall RA, Huvenne VAI (2019) Using 3D photogrammetry from ROV video to quantify cold-water coral reef structural complexity and investigate its influence on biodiversity and community assemblage. Coral Reefs. https://doi.org/10.1007/s00338-019-01827-3

Quinn NJ, Kojis BL (2003) The dynamics of coral reef community structure and recruitment patterns around Rota, Saipan, and Tinian. Western Pacific Bull Mar Sci 72(3):979-996

Raj KD, Mathews G, Bharath MS, Laju RL, Kumar PD, Arasamuthu A, Edward JP (2018) Cushion star (Culcita schmideliana) preys on coral polyps in Gulf of Mannar. Southeast India Mar Fres Behav Phys 51(2):125-129

Rice MM, Ezzat L, Burkepile DE (2019) Corallivory in the Anthropocene: interactive effects of anthropogenic stressors and corallivory on coral reefs. Front Mar Sci 5:525

Richardson LE, Graham NA, Pratchett MS, Hoey AS (2017) Structural complexity mediates functional structure of reef fish assemblages among coral habitats. Env Biol Fish 100(3):193-207

Risk MJ (1972) Fish diversity on a coral reef in the Virgin Islands. Atoll Res Bull 153:2-6

Rivera-Posada J, Caballes CF, Pratchett MS (2014) Size-related variation in arm damage frequency in the crown-of-thorns sea star, Acanthaster planci. J Coast Life Med 2:187-195

Rogers TL, Elliott JK (2013) Differences in relative abundance and size structure of the sea stars Pisaster ochraceus and Evasterias troschelii among habitat types in Puget Sound, Washington, USA. Mar Bio 160(4):853-865

Rossi P, Ponti M, Righi S, Castagnetti C, Simonini R, Mancini F et al (2021) Needs and gaps in optical underwater technologies and methods for the investigation of Marine Animal forest 3Dstructural complexity. Front Mar Sci 8:171

Rotjan RD, Lewis SM (2008) Impact of coral predators on tropical reefs. Mar Ecol Prog Ser 367:73-91

Saponari L, Montano S, Seveso D, Galli P (2014) The occurrence of an Acanthaster planci outbreak in Ari Atoll, Maldives. Mar Biodiv 45:599-600

Saponari L, Montalbetti E, Galli P, Strona G, Seveso D, Dehnert I, Montano S (2018) Monitoring and assessing a 2-year outbreak of the corallivorous seastar Acanthaster planci in Ari Atoll. Republic of Maldives Env Mon Ass 190(6):1-12

Saponari L, Dehnert I, Galli P, Montano S (2021) Assessing population collapse of Drupella spp. (Mollusca: Gastropoda) 2 years after a coral bleaching event in the Republic of Maldives. Hydrobiologia 1-14

Seveso D, Montano S, Strona G, Orlandi I, Vai M, Galli P (2012) Upregulation of $\mathrm{Hsp} 60$ in response to skeleton eroding band disease but not by algal overgrowth in the scleractinian coral Acropora muricata. Mar Env Res 78:34-39

Seveso D, Montano S, Reggente MAL, Orlandi I, Galli P, Vai M (2015) Modulation of Hsp60 in response to coral brown band disease. Dis Aquat Organ 115(1):15-23

Stella JS, Munday PL, Jones GP (2011) Effects of coral bleaching on the obligate coral-dwelling crab Trapezia cymodoce. Coral Reefs 30(3):719-727

Storlazzi CD, Dartnell P, Hatcher GA, Gibbs AE (2016) End of the chain? Rugosity and fine-scale bathymetry from existing underwater digital imagery using structure-from-motion (SfM) technology. Coral Reefs 35(3):889-894 
Thomassin BA (1976) Feeding behaviour of the felt-, sponge-, and coral-feeder sea stars, mainly Culcita schmideliana. Helg Wissen Meeresunt 28(1):51-65

Tkachenko KS (2015) Impact of repetitive thermal anomalies on survival and development of mass reef-building corals in the Maldives. Mar Ecol 36(3):292-304

Todd PA (2008) Morphological plasticity in scleractinian corals. Biol Rev 83(3):315-337

Urbina-Barreto I, Chiroleu F, Pinel R, Fréchon L, Mahamadaly V, Elise S et al (2021) Quantifying the shelter capacity of coral reefs using photogrammetric $3 \mathrm{D}$ modeling: from colonies to reefscapes. Ecol Indic 121:107151

Vanderploeg HA, Scavia D (1979) Calculation and use of selectivity coefficients of feeding: zooplankton grazing. Ecol Model 7(2):135-149

Ventura D, Dubois SF, Bonifazi A, Jona Lasinio G, Seminara M, Gravina MF, Ardizzone G (2021) Integration of close-range underwater photogrammetry with inspection and mesh processing software: a novel approach for quantifying ecological dynamics of temperate biogenic reefs. Remote Sens Ecol Conserv 7:169-186. https://doi.org/10.1002/rse2.178

Weil E, Torres JL, Ashton M (2005) Population characteristics of the sea urchin Diadema antillarum in La Parguera, Puerto Rico, 17 years after the mass mortality event. Rev Bio Trop 53(3):219-231

Westoby MJ, Brasington J, Glasser NF, Hambrey MJ, Reynolds JM (2012) "Structure-from-Motion" photogrammetry: a low-cost, effective tool for geoscience applications. Geomorphology 179:300-314

Wilmes JC, Schultz DJ, Hoey AS, Messmer V, Pratchett MS (2020) Habitat associations of settlement-stage crown-of-thorns starfish on Australia's Great Barrier Reef. Coral Reefs 39:1163-1174

Wolf AT, Nugues MM, Wild C (2014) Distribution, food preference, and trophic position of the corallivorous fireworm Hermodice carunculata in a Caribbean coral reef. Coral Reefs 33(4):1153-1163

Young GC, Dey S, Rogers AD, Exton D (2017) Cost and timeeffective method for multiscale measures of rugosity, fractal dimension, and vector dispersion from coral reef 3D models. PLoS ONE 12(4):e0175341

Zar JH (1999) Biological statistics. Prentice Hall, Upper Saddle River, NJ

Publisher's Note Springer Nature remains neutral with regard to jurisdictional claims in published maps and institutional affiliations. 